\title{
Chronic subordination stress induces hyperphagia and disrupts eating behavior in mice modeling binge-eating-like disorder
}

\author{
Maria Razzoli ${ }^{1}$, Valentina Sanghez ${ }^{1,2 \dagger}$ and Alessandro Bartolomucci ${ }^{1 *}$ \\ 1 Department of Integrative Biology and Physiology, University of Minnesota, Minneapolis, MN, USA \\ ${ }^{2}$ Department of Neuroscience, University of Parma, Parma, Italy
}

Edited by:

Suzanne E. Judd, University of

Alabama at Birmingham, USA

Reviewed by:

Andrew Brown, University of

Alabama at Birmingham, USA

Antonio Torsello, University of

Milano-Bicocca, Italy

${ }^{*}$ Correspondence:

Alessandro Bartolomucci,

Department of Integrative Biology

and Physiology, University of

Minnesota, 2231 6th Street SE,

Minneapolis, MN 55455, USA

e-mail: abartolo@umn.edu

\section{${ }^{\dagger}$ Present address:}

Valentina Sanghez, Division-Medical Genetics, Department of Pediatrics, LABiomed Research Institute at Harbor UCLA Medical Center, Torrance, CA, USA

\begin{abstract}
Background: Eating disorders are associated with physical morbidity and appear to have causal factors like stressful life events and negative affect. Binge-eating disorder (BED) is characterized by eating in a discrete period of time a larger than normal amount of food, a sense of lack of control over eating, and marked distress. There are still unmet needs for the identification of mechanisms regulating excessive eating, which is in part due to the lack of appropriate animal models. We developed a naturalistic murine model of subordination stress-induced hyperphagia associated with the development of obesity. Here, we tested the hypotheses that the eating responses of subordinate mice recapitulate the BED and that limiting hyperphagia could prevent stress-associated metabolic changes.
\end{abstract}

Methods: Adult male mice were exposed to a model of chronic subordination stress (CSS) associated with the automated acquisition of food intake and we performed a detailed meal pattern analysis. Additionally, using a pair-feeding protocol we tested the hypothesis that the manifestation of obesity and the metabolic syndrome could be prevented by limiting hyperphagia.

Results: The architecture of feeding of subordinate mice was disrupted during the stress protocol due to disproportionate amount of food ingested at higher rate and with shorter satiety ratio than control mice. Subordinate mice hyperphagia was further exacerbated in response to either hunger or to the acute application of a social defeat. Notably, the obese phenotype but not the fasting hyperglycemia of subordinate mice was abrogated by preventing hyperphagia in a pair-feeding paradigm.

Conclusion: Overall, these results support the validity of our CSS to model BED allowing for the determination of the underlying molecular mechanisms and the generation of testable predictions for innovative therapies, based on the understanding of the regulation and the control of food intake.

Keywords: obesity, pair feeding, meal-pattern analysis, ghrelin, glucose

\section{INTRODUCTION}

A substantial number of obese individuals report binge-eating episodes, psychiatric conditions, stressful life events, more medical complaints, and a poorer quality of life $(1-4)$. At the same time, stress and negative affect are increasingly recognized as risk factors for binge-eating and obesity (4-7). The parallel increase in incidence of seemingly independent psychiatric and metabolic diseases has long been suspected to be due to common causal factors.

Binge eating is currently included as an eating disorder in the Diagnostic and Statistical Manual of Mental Disorders [DSMV, 5th ed.; (2)]. Binge-eating disorder (BED) is characterized by recurrent episodes of ingestion of large amount of food in discrete periods of time accompanied by feelings of loss of control and marked distress in the absence of compensatory behaviors such as purging, fasting, or excessive exercise. The difficulty to identify causal factors and underlying molecular mechanisms in humans makes animal models very valuable and needed to address mechanistic questions.

Unfortunately, current animal models do not recapitulate key traits of binging in humans and so far none matches the diagnostic symptoms of binging associated with obesity. Available animal models of binging are often based on a combination of acute stress exposure plus repeated cycles of food deprivation (8-10). Strikingly, most binge eating in humans is not driven by hunger or metabolic demands and most patients are overweight or obese [5th ed.; DSM-V; $(2,8,11)]$. At the same time, a significant number of individuals with BEDs report the onset of binges prior to dieting (12). Experimental animals from current models do not show significant increases in body weight/adiposity $(13,14)$, while the rebound hyperphagic response after fasting provides evidence that they are in an energy-deficient state $(8,9)$. 
Over the years, we developed a naturalistic mouse model of chronic subordination stress (CSS) by which subordinate animals develop a complex behavioral and metabolic syndrome characterized by up-regulated hypothalamus-pituitary-adrenocortical axis functioning (increased plasma corticosterone, impaired negative feedback in the dexamethasone suppression test, downregulated hippocampal glucocorticoids receptors) $(15,16)$, behavioral depression-like disorders (depression of activity, anhedonia, social withdrawal $)(15,16)$ as well as autonomic and immuneendocrine changes $(15,16)$. Importantly, hyperphagia arises spontaneously in subordinate mice and under a high-fat diet it is associated with vulnerability to obesity, metabolic-like, and type2 diabetes-like syndromes (17-22). Arguably, this hyperphagic response represents the most robust phenotype in subordinate mice. Conversely, dominant animals do not manifest anxiety or depression-like behavior $(17,19)$ and develop a marked negative energy balance whereby hyperphagia is a mechanism to compensate for increased energy demands [(18, 21, 23); unpublished]. Based on previous data, here we set out to test the hypothesis that hyperphagia in subordinate animals has key features of bingeeating-like disorders. Furthermore, we also tested the hypothesis that selectively preventing hyperphagia with a pair-feeding protocol will be sufficient to limit the development of diet-induced obesity (21).

\section{MATERIALS AND METHODS ANIMALS}

Ten- to twelve-week-old male Swiss CD1 mice $(n=69)$ were purchased from Charles River Laboratories and 10-12 weeks old male C57Bl6/J mice $(n=112)$ were purchased from Jackson Laboratories. All mice were maintained in a 12:12 hour light:dark cycle (lights on at 05:00 hours) at $22 \pm 2{ }^{\circ} \mathrm{C}$. Mice were fed a standard diet (2018 Tecklad, Harlan; $3.1 \mathrm{kcal} / \mathrm{g}, 18 \% \mathrm{kcal}$ from fat) unless otherwise specified. Animals were maintained and cared for in accordance with the NIH Guide for the Care and Use of Laboratory Animals. Experimental procedures were approved by the University of Minnesota Animal Care and Use Committee. The pair-feeding experiment was conducted at the University of Parma Italy using the same experimental conditions and experiments approved by local ethical committees of University of Parma and approved by the Italian Ministry of Health.

\section{MOUSE MODEL OF CHRONIC SUBORDINATION STRESS}

The protocol used represents a modified version of our previously published procedure $(18,20,24)$. The experiment consisted of a 1-week pre-stress baseline phase and 4 weeks of CSS phase. During baseline, subjects were individually housed. During the 4 weeks following baseline, each CD1-resident mouse received an unfamiliar C57BL6/J or CD1 intruder mouse and the two animals were allowed to freely interact daily for $10 \mathrm{~min}$, between 08:30 a.m. and 09:30 a.m. The same dyad remained paired for the total duration of the study. After the interaction leading to the social defeat of the C57BL6/J and one of the two CD1 mice, the two animals were separated by means of a wire-mesh partition thus allowing continuous sensory contact but no physical interaction. During the social interaction, offensive behaviors of the animals were manually recorded and mice social status was determined as previously established and detailed (17,24). During the social interaction, offensive behaviors of the animals were manually recorded and subordinate mice social status was defined by the display of upright posture, flight behavior, and squeaking vocalization. Only dyads that reliably showed a stable dominant/subordinate hierarchy and in which the subordinate showed no attack after the fourth day of interaction were included in the study. Subordinate mice of both CD1 and C57BL6/J strains represented the experimental subjects in this series of experiments. Controls were represented by age, strain, and sex matched male mice housed in groups of three siblings that based on previous observations show no sign (immuno-endocrine and behavioral) of stress [see Ref. $(24,25)$ for further details]. Control animals were housed in group of 3 (from pre-existing groups of four to five animals per cage) the same day in which the chronic psychosocial stress procedure started and were received all the experimental manipulations as the experimental subjects except those involving the subordination stress. To conduct a detailed meal pattern analysis, individually housed mice were used as controls in specific experiments described below. Body weight gain was monitored weekly. Food intake was measured every other day (or as otherwise specified) during the baseline and stress phases. Food intake for group housed mice was divided for the number of animals in the cage.

\section{MEAL-PATTERN ANALYSIS DURING CHRONIC SUBORDINATION STRESS}

The BioDAQ episodic Food Intake Monitor for mice (BioDAQ, Research Diets, Inc., New Brunswick, NJ, USA) was used to investigate the microstructure of feeding. This made possible the continuous monitoring of meal pattern in the mouse housing-cage on a subset of control and subordinate subjects. During baseline, mice were individually housed and habituated to feeding through a low spill food hopper placed on an electronic balance mounted on the animal home cage. During the stress phase, the BioDAQ sensors and hoppers were fitted to the side of the CD1 resident cage where the C57BL6/J subject mouse was to be housed to continue the continuous monitoring of meal pattern with the exception of the daily social interaction, when the recording of feeding behavior was interrupted. In order to determine an accurate meal pattern analysis, control mice were maintained in individual home-cages fitted with the food hopper and the BioDAQ sensor as during baseline. The BioDAQ system records feeding bouts (changes in stable weight before and after a bout) as feeding bout vectors with a start time, duration, and amount consumed. Bouts are separated by an inter-bout interval, and meals consist of one or more bouts separated by an inter-meal interval. Meal pattern parameters were defined according to previously published literature (26-28). Meals were defined as feeding bouts occurring within $5 \mathrm{~min}$ of the previous response and with their sum equal to or greater than $0.02 \mathrm{~g}$. If bouts of feeding were $>5 \mathrm{~min}$ apart, they were considered as a new meal. Meal parameters assessed included meal frequency (number/period), meal size (grams/meal), meal duration (seconds/meal), total meal time (seconds/period), post-meal interval (PMI in seconds), eating rate (milligrams/minute), and the satiety ratio [calculated as the average PMI divided by the average meal size (minutes/gram food eaten)]. Parameters were calculated by 
the software provided by the manufacturer (BioDAQ Monitoring Software 2.2.02).

\section{ACUTE STRESS- AND HUNGER-INDUCED BINGE EATING}

The impact of CSS on the acute immediate consequences of a single social defeat on eating was determined measuring food intake during $6 \mathrm{~h}$ following social defeat on the first and 14th day of the stress phase.

Hunger-induced hyperphagia was monitored across $24 \mathrm{~h}$ following overnight fasting. Mice were not defeated on the testing day.

\section{PAIR-FEEDING PROTOCOL DURING CHRONIC SUBORDINATION STRESS}

To limit spontaneous hyperphagia and investigate its mechanistic role in stress-induced obesity, we used a pair-feeding protocol [i.e., preventing hyperphagia by pair-feeding mice to normal food intake; (29)]. CD1 mice were exposed to standard diet during baseline and the first week of chronic stress to establish dominance. High-fat diet (HFD, D12451 from Research Diets, Inc., New Brunswick, NJ, USA; $20 \% \mathrm{kcal}$ protein, 35\% kcal carbohydrate, $45 \% \mathrm{kcal}$ from fat) was provided during the subsequent 3 weeks of chronic stress (18). Subordinate mice were pair fed to their baseline food intake during the first week of stress, while during the 3 weeks of HFD they were pair fed to food ingested by the control group (therefore, the normal transient hyperphagic response to palatable diet-induced shown by control mice was not prevented). Body weight and food intake were measured daily. Every day at 9:30 a.m., pair fed mice were allocated the food calculated on the basis of the amount of food that they consumed during baseline (week 1 on standard diet); during the following weeks (3 weeks on HFD), the mice were assigned the amount of food corresponding to the average amount consumed by all control mice the day before and normalized according to the subject's respective weight.

\section{Glucose tolerance tests}

At the end of the stress phase, mice were subjected to an overnight fast $(12 \mathrm{~h})$ to then be sampled for blood glucose levels from tail bleeding at $0,30,60$, and 120 min after intra-peritoneal injection of $0.1 \mathrm{cc} / 10 \mathrm{~g}$ body weight of $\mathrm{D}$-glucose at $10 \%$ dissolved in sterile saline solution (corresponding to $1 \mathrm{~g} / \mathrm{kg}$ body weight). All blood glucose measurements were done using Accucheck Aviva glucometer (Roche Diagnostics, Indianapolis, IN, USA). The area under the curve (AUC) data for GTT were calculated according to the trapezoid rule and including all incremental area below the curve and expressed as milligram/deciliter* $120 \mathrm{~min}, \times 10^{3}$.

\section{TERMINAL MEASURES}

Mice were fasted overnight before sacrifice. At autopsy, adipose fat mass was dissected and weighted. Glucose was measured as detailed above from plasma samples, while corticosterone and total ghrelin levels were measured in plasma with xMAP or ELISA commercially available kits (Bio-Rad and Millipore).

\section{DATA ANALYSIS}

Data were analyzed with Statistica (Statsoft, Inc., Tulsa, OK, USA). Repeated measures ANOVA followed by Tukey's HSD post hoc tests for binary comparisons was used for meal-pattern analysis parameters, acute hyperphagia time course, and GTT; one-way ANOVA followed by Tukey's HSD post doc was used for single time acute hyperphagia after hunger or stress, perigonadal white adipose tissue (WAT) weight, ghrelin, glucose, corticosterone levels, and GTT AUC. Repeated measures ANCOVA and

A

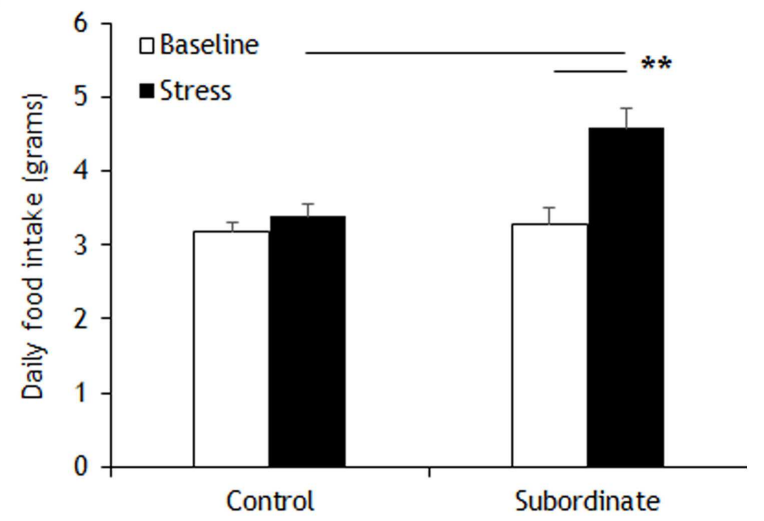

B

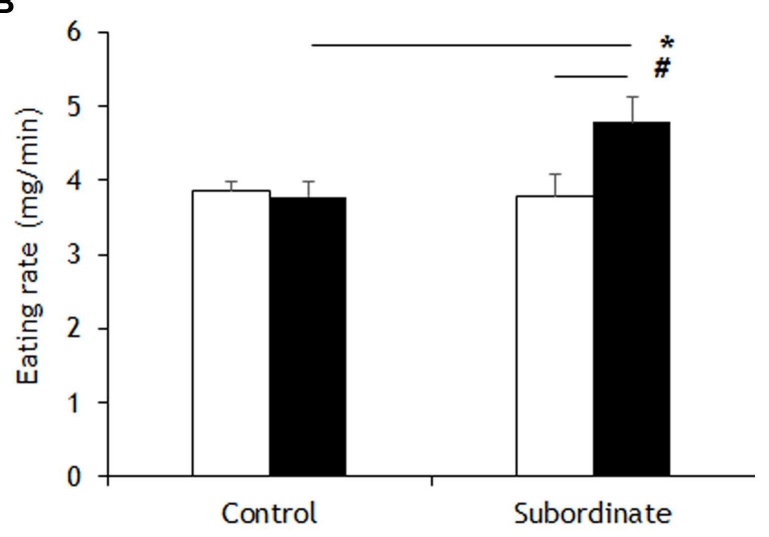

C

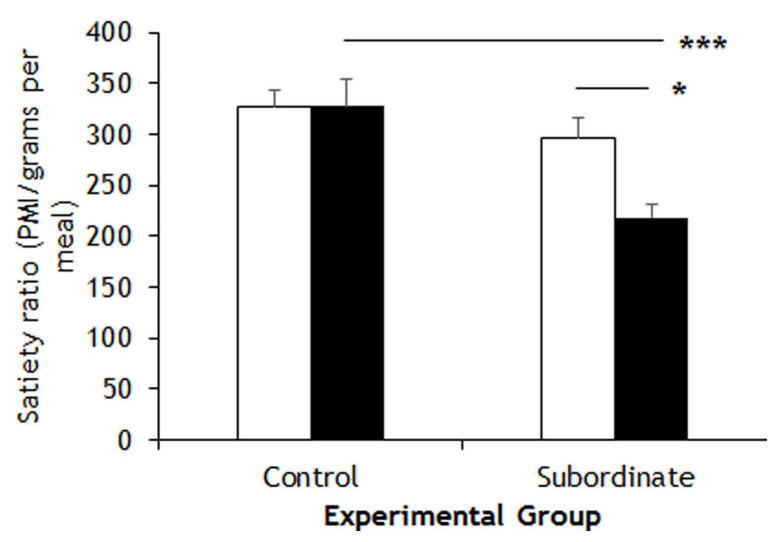

FIGURE 1 | Meal-pattern analysis highlighted increased food intake in subordinate C57BL/6J mice (A) that was associated to a faster feeding rate (B) and to a shorter satiety ratio (C) than baseline and/or controls Data represent group averages \pm SEM. Control: $N=7$; subordinate: $N=5$. ${ }^{*} p=0.055,{ }^{*} p<0.05,{ }^{*}{ }^{*} p<0.01,{ }^{* * *} p<0.001$. 
Table 1 | Meal-pattern parameters that did not correspond to any significant differences between groups

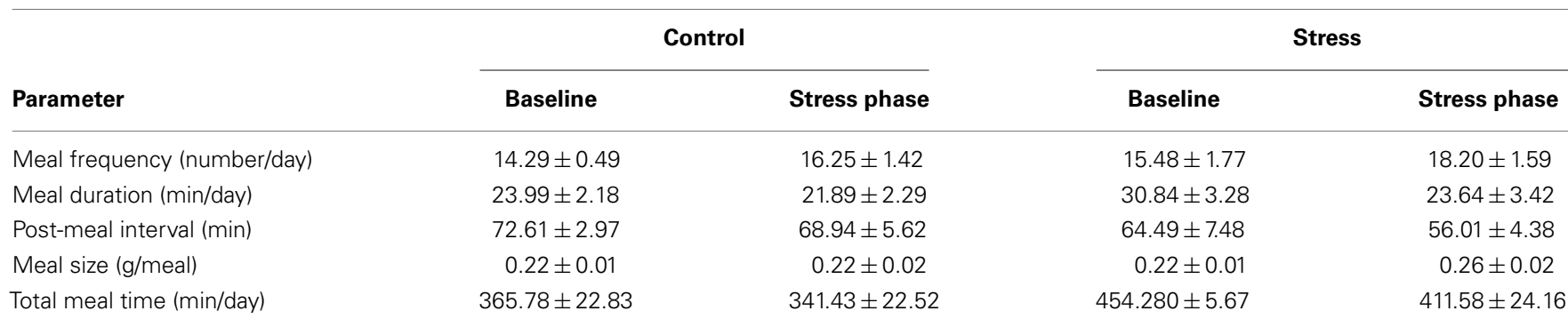

Data represent group averages $\pm S E M$. Control $N=7$; subordinate $N=5$

Bonferroni-Holm corrected planned comparisons for binary contrasts were used for food intake and body weight time courses in the pair-feeding experiment using the respective baseline values as covariates; Significance was set at $p<0.05$ or lower.

\section{RESULTS \\ CHRONIC SUBORDINATION STRESS REPLICATES KEY TRAITS OF BINGE-EATING DISORDER}

The CSS model has proven a valuable tool to induce a positive energy balance in male mice of various strains including CD1, C57BL6/J, 129SVEV, and others (19-22, 30). Hyperphagia develops shortly after exposing the mice to subordination stress; it remains sustained throughout the stress exposure and is associated to higher body weight gain compared to controls (21). A detailed analysis of control and subordinate mice eating behavior was conducted through an automatic food monitoring system and a dedicated software generating a meal-pattern analysis. Overall, our analysis revealed a consistent CSS-induced disruption of the meal architecture, which is consistent with a BED. The overall amount of food consumed by subordinate mice was significantly greater than during baseline $[F(1,10)=16.50, p<0.01]$ and compared to controls $[F(1,10)=8.445, p<0.05]$ (Figure 1A). In line with derangements toward a BED-like syndrome, the eating rate was significantly increased $[F(1,10)=6.13, p<0.05]$ (Figure 1B), while the satiety ratio was significantly decreased by CSS [interaction $F(1,10)=8.77, p<0.05$. Figure 1C). Conversely, meal frequency, duration, and size, as well as post-meal interval and total meal time were not different between subordinate and control group (Table 1), suggesting that only specific components of satiation were targeted by stress. The lack of changes in other meal parameters could be a compensatory response or imply that long term control of feeding remained intact.

\section{CSS ENHANCES THE SUSCEPTIBILITY TO ACUTE HUNGER- AND STRESS-INDUCES BINGE-EATING EPISODE}

Increased hunger- and stress-induced hyperphagia are classically accepted as behavioral markers of BED (10,31). Hungerinduced hyperphagia was here assessed in both CD1 and C57BL6/J mice in a fasting-refeeding protocol. Subordinate CD1 mice ingested a significantly larger amount of food compared to controls $[F(1,23)=21.88, p<0.001]$ (Figure 2A). Similarly, in the $6 \mathrm{~h}$ after a single episode of social defeat on the 14th day of the CSS, subordinate mice showed increased food intake $[F(1,25)=5.32, p<0.05]$ (Figure 2B). Furthermore, we repeated and extended this observation by using the automated analysis of food intake system. During $6 \mathrm{~h}$ immediately following the social defeat, meal intake was significantly increased in subordinate C57BL6/J mice $[F(2,8)=7.12, p<0.05]$ (Figure 3A) with a maximal intake occurring after 14 days of stress $(p<0.05)$. Interestingly, meal duration showed a biphasic effect $[F(2,8)=16.23$, $p<0.01$ ] (Figure 3B) being increased on the first day of stress compared to baseline $(p<0.05)$ and being reduced at day 14 $(p<0.01)$. Nevertheless, the number of meals exhibited by subordinate mice throughout the stress exposure did not change over time (Figure 3C).

\section{STRESS-INDUCED HYPERPHAGIA IS REQUIRED FOR THE DEVELOPMENT OF OBESITY IN OUR ANIMAL MODEL}

After having established that CSS leads to features of BED, we directly tested the hypothesis that hyperphagia is required for the development of weight gain, fat mass increase, and glucose intolerance in CD1 animals fed an HFD as previously established (21). To test this hypothesis, hyperphagia was prevented by pairfeeding subordinate mice an amount of food similar to pre-stress food intake or control mice (Figure 4A). Importantly, pair feeding prevented CSS-induced weight gain (Figure 4B) and increased adiposity (Figure 4C) shown by ad libitum fed mice [food intake: $F(2,49)=11.62, p<0.001$; body weight: $F(2,55)=13.44$, $p<0.001$; pWAT $F(1,56)=3.4577, p<0.05]$. Interestingly, total ghrelin was significantly decreased by CSS in ad libitum fed mice and normalized by pair feeding $[F(2,26)=7.49, p<0.001]$ (Figure 4D).

Despite pair feeding preventing the development of obesity, it did not prevent the development of hyperglycemia while it improved glucose tolerance. Indeed, pair-fed subordinate mice showed higher fasting hyperglycemia than both control and ad libitum fed subordinate mice $[F(2,53)=16.072, p<0.001]$ (Figure 4E). This result can be explained by the very high level of fasting corticosterone observed in pair-fed stressed animals $[F(2,45)=7.6222, p<0.01]$ (Figure 4F). Additionally, despite pair-fed CSS mice having a significant hyperglycemia compared to ad libitum fed CSS mice, the glucose level of the two stressed groups was indistinguishable after glucose injection $[F(2,44)=8.61$, $p<0.001$ ] (Figure 4G), which resulted in a significantly lower AUC for the pair-fed CSS compared to the ad libitum CSS group $[F(2,42)=53.58 \mathrm{E}+06, p<0.01]$ (Figure 4H), overall suggestive of improved glucose tolerance in the pair fed CSS compared to ad libitum fed CSS mice. 


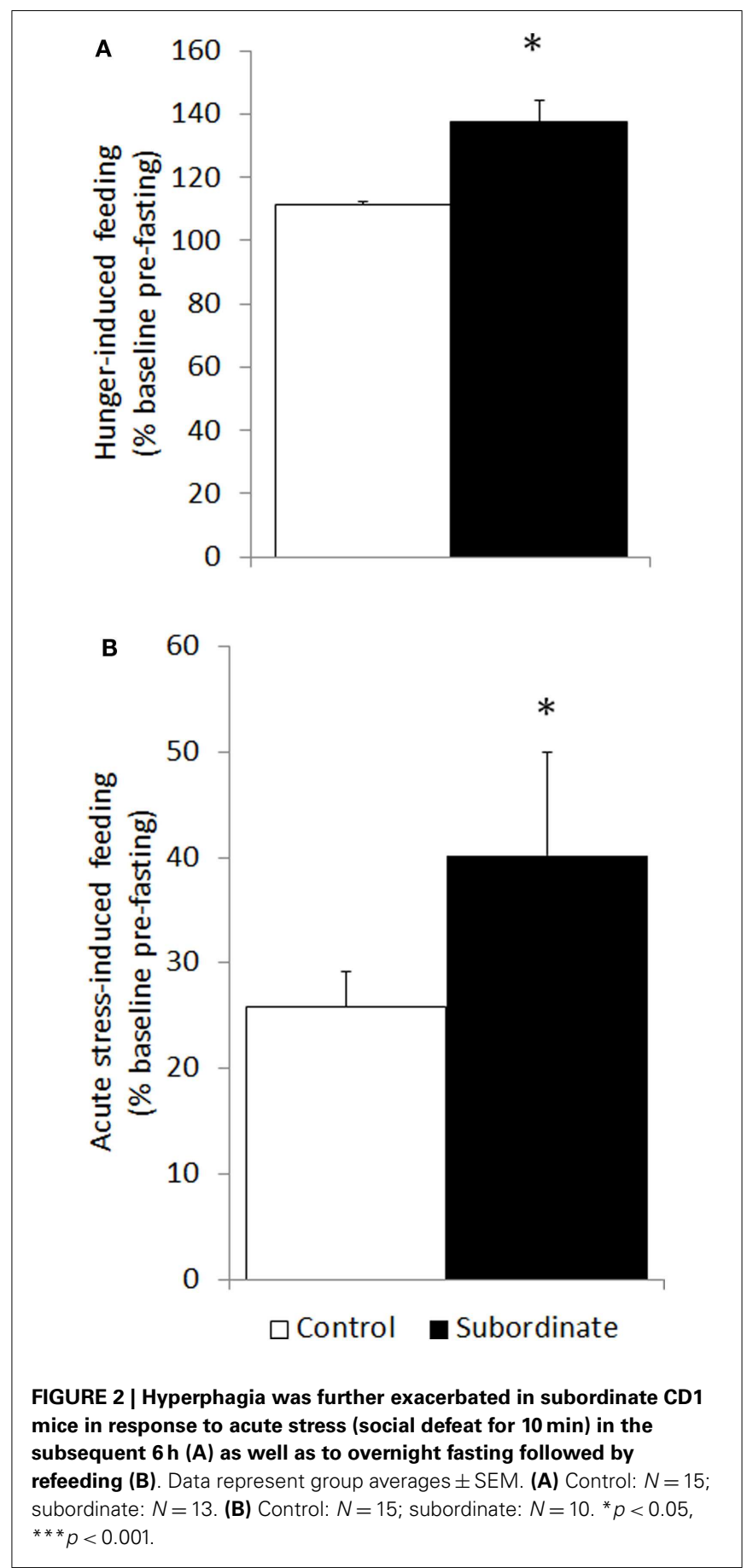

\section{DISCUSSION}

In the present study, we demonstrated that the outcome of CSS model resembles many features of human BED. Spontaneous hyperphagia is one of the most robust phenotypes observed in mice exposed to the chronic psychosocial stress model [present work; $(17-20,22)]$ as well as in similar animal models of social stress $(32,33)$. Subordinate mice spontaneously developed vigorous hyperphagia ( $30-40 \%$ than baseline) characterized by early onset (1-2 days) and lack of habituation (i.e., up to 4 weeks).

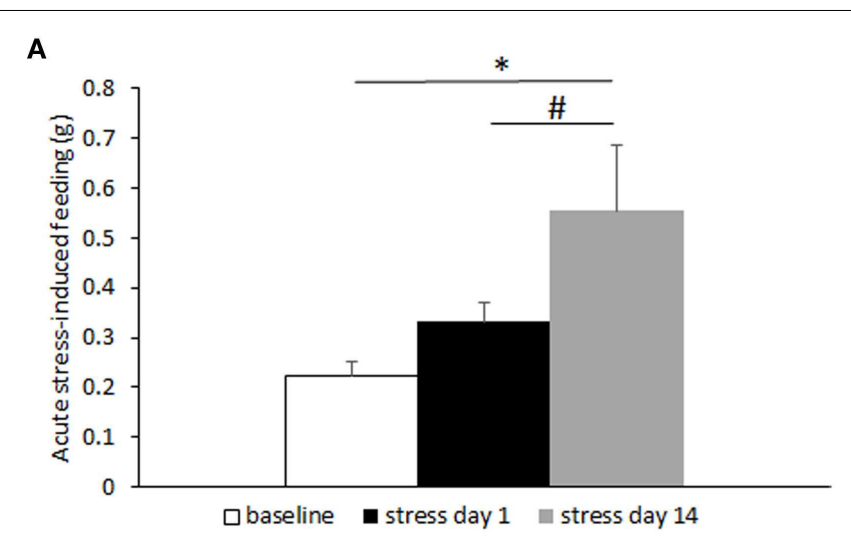

B

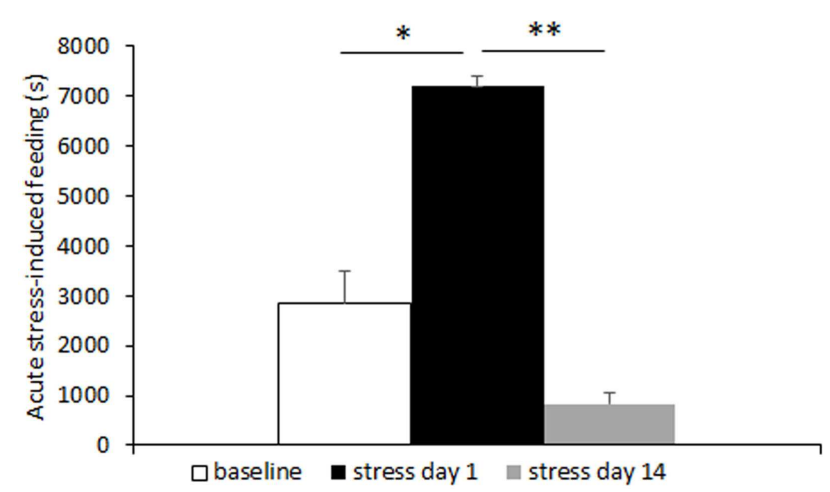

C

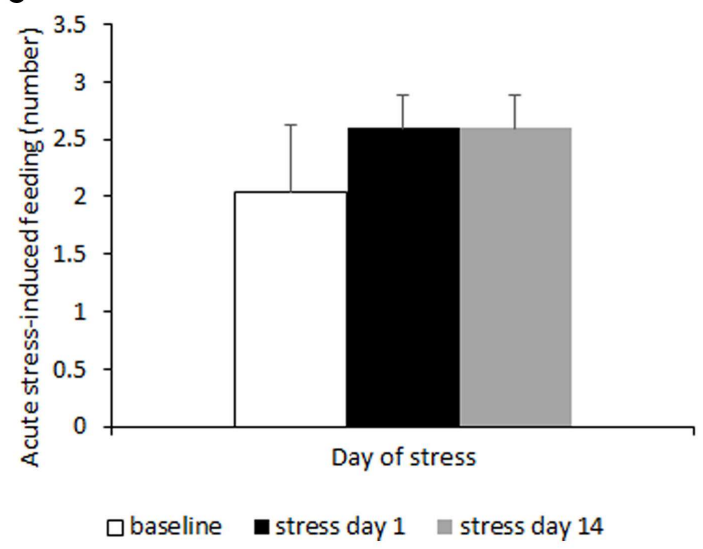

FIGURE 3 | Meal-pattern and time-course analysis of acute stress-induced hyperphagia in C57BL/6J mice. Meal intake was increased over time in subordinate (A), while meal duration (B) was initially increased to later on diminish in correspondence with a meal frequency that remained stable over time (C). Data represent group averages \pm SEM. Control: $N=7$; subordinate: $N=5 .{ }^{*} p=0.055,{ }^{*} p<0.05,{ }^{*} p<0.01$.

Importantly, we previously showed that hyperphagia develops in absence of increased energy expenditure $(21,23)$ and in presence of depression of locomotor activity $(18-20,30)$ thus excluding a compensatory hyperphagia. In light of these evidences and of the behavioral characterization of the subordinate mice as a model of 

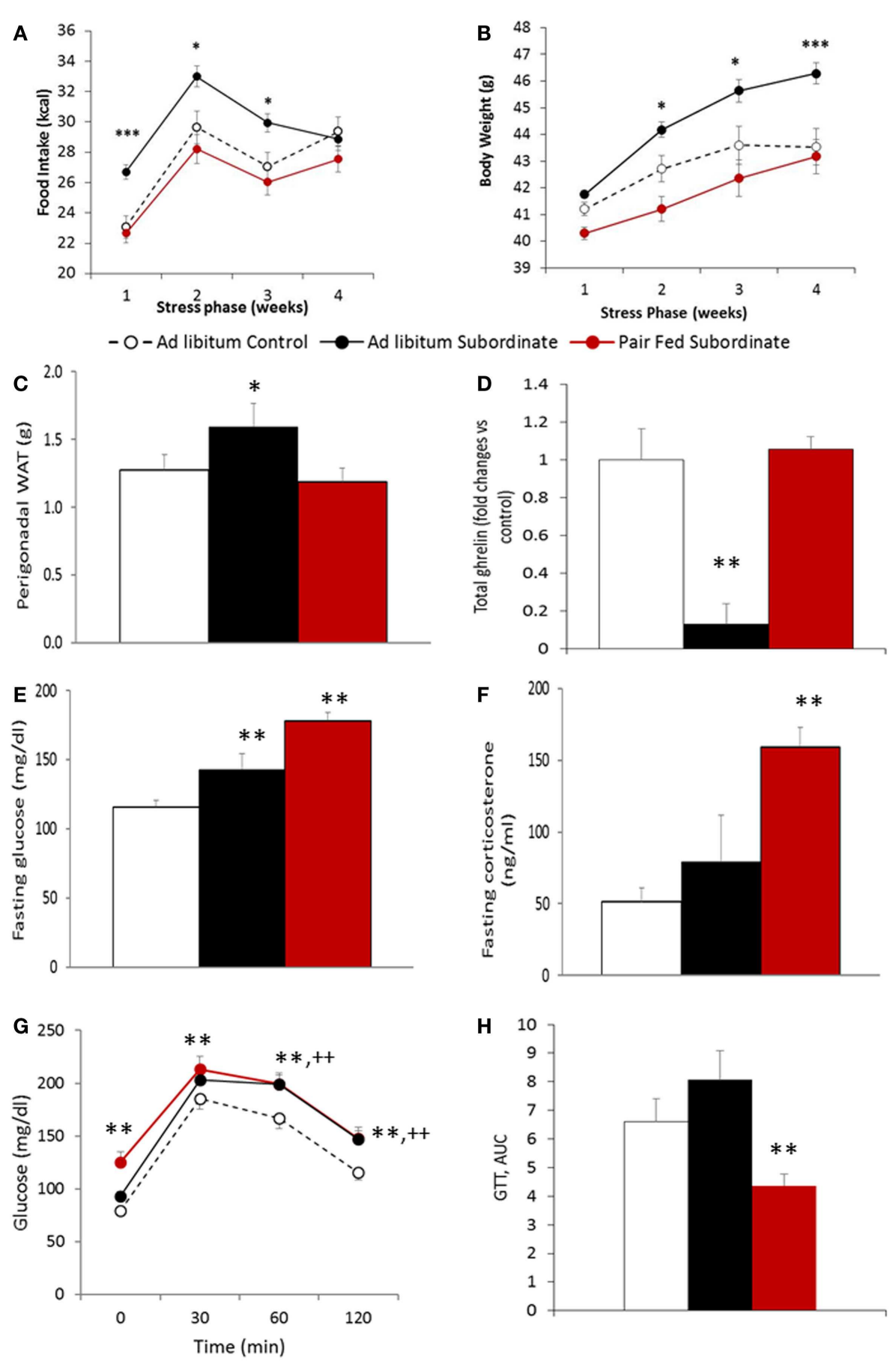

FIGURE 4 | Pair-feeding subordinate mice prevents stress-induced vulnerability to diet-induced obesity. (A) Food intake, data are presented as least square means \pm SEM; the covariate is the baseline food intake, average $=22.5 \mathrm{kcal}[F(1,49)=22.24, p<0.01$; ad libitum fed control: $N=12$; ad libitum fed subordinate: $N=28$; pair fed subordinate: $N=13$ ]; (B) body weight gain, data are presented as least square means \pm SEM; the covariate is the baseline body weight, average $=41.2 \mathrm{~g}[F(1,55)=198.37, p<0.001$; ad libitum fed control: $N=22$; ad libitum fed subordinate: $N=34$; pair fed subordinate: $N=13$ ]; (C) perigonadal white adipose tissue (WAT) [ad libitum fed control: $N=12$; ad libitum fed subordinate: $N=26$; pair fed subordinate:

$N=12$ ]; (D) total ghrelin [ad libitum fed control: $N=5$; ad libitum fed subordinate: $N=6$; pair fed subordinate: $N=8$ ]; (E) glucose [ad libitum fed control: $N=21$; ad libitum fed subordinate: $N=26$; pair fed subordinate: $N=9$ ]; (F) corticosterone [ad libitum fed control: $N=17$; ad libitum fed subordinate: $N=23$; pair fed subordinate: $N=8$ ]; $(\mathbf{G}, \mathbf{H})$ glucose tolerance test [ad libitum fed control: $N=16$; ad libitum fed subordinate: $N=19$; pair fed subordinate: $N=13$ ]. (D-H) Data represent group averages $\pm S E M$, ${ }^{*} p<0.05,{ }^{* *} p<0.01,{ }^{* * *} p<0.001$ vs. control. In (G), ** refer to binary comparisons between pair fed subordinate and control mice, while ++ refer to binary comparisons between ad libitum fed subordinate and control mice. 


\section{Table 2 | A comparison between symptoms of binge-eating disorder (DSM-V) and effects seen in subordinate mice under chronic subordination} stress.

\section{Diagnostic criteria for the diagnosis of binge-eating disorder (DSM-V) Effect in our animal model}

A. Recurrent episodes of binge eating characterized by both of the

following

1. Eating, in a discrete period of time, an amount of food that is larger than normal.

1. Increased eating rate (g of food/min). Acute stress/hunger-induced hyperphagia

2. A sense of lack of control over eating during the episode.

2. Decreased satiety ratio

B. The binge-eating episodes are associated with three (or more) of the following

1. Eating much more rapidly than normal

1. Shorter meals revealed by meal pattern

2. Eating until feeling uncomfortably full

3. Eating large amounts of food when not feeling physically hungry

2. Not applicable or not available

3. Short interval between feeding bouts revealed by meal pattern analysis. High acute stress-induced feeding during the light phase

4. Eating alone because of feeling embarrassed by how much one is eating

4. Not applicable or not available

5. Feeling disgusted with oneself, depressed, or very guilty after overeating

5. Development of depression-like disorder

C. Marked distress regarding binge eating

C. Biomarkers of stress and acute stress-induced hyperphagia

D. The binge eating occurs at least once a week for 3 months

D. Recurrent episodes of binge eating during the entire stress phase

E. The binge eating is not associated with the recurrent use of

E. Not applicable or not available

inappropriate compensatory behavior (such as purging).

depression-like disorder $(15,17,19,20)$, we hypothesized that the observed hyperphagia can be considered as a specific eating disorder phenotype having a strong validity for modeling human binge eating associated with obesity $(1-5,34,35)$. Accordingly, we tested in our model the specific criteria used for the diagnosis of BED in human (Table 2). Specifically, we explored the microstructure of spontaneous daily feeding behavior as well as the structure of the feeding response in response to acute episodes of hunger and stress $(36,37)$. It was demonstrated that the overall hyperphagia is indeed the result of an increased amount of ingested food, which subordinate mice consume at higher rate and with reduced satiety ratio than control mice. The observed decreased satiety ratio (Figure 1C) point toward a reduced effectiveness of food ingestion to induce satiety (38), while the increased rate of food intake (Figure 1B) would reflect feeding while eating in a perceived stressful situation as feeding rate is known to be augmented by stress (39) and in social feeding in subordinate individuals (40).

Interestingly, the sustained hyperphagia induced in subordinate mice could be further exacerbated acutely in response to either hunger or social defeat, both of which triggered increased amount of food intake over discrete periods of time. The feeding microstructure analyzed in the immediate sequelae of individual social defeat showed that eating behavior of subordinate mice lasted longer and was composed of a higher number of meals on the day on the first social defeat episode in the CSS protocol. The alteration of meal structure due to subordination stress changed over time. When assessed at day 14 in the subordination stress phase, the feeding activity of subordinate mice had evolved into an eating paroxysm, as their behavior consisted of a maximal amount of food consumed over much shorter meal times. Overall, these results allow to validate the CSS accordingly to the defining criteria of a BED model (9) (Table 2): (1) the behavior occurs repeatedly over an extended period of time; (2) binging animals consume more food in brief, discrete, periods of time than controls do under similar circumstances. (3) if compensatory behavior is present, it should be initiated by the animal rather than imposed by the investigator. It is also worth to point out that this behavior was observed during a phase of the day corresponding to the natural mice resting phase $(6 \mathrm{~h}$ following dominant/intruder interaction, with social defeat being carried out between 8:30 a.m. and 9:30 a.m.). Interestingly, in obese populations, BED has been linked with night-eating syndrome (41-44) and nocturnal snacking $(45,46)$.

Another important feature of our model is that binge eating develops spontaneously and is associated with derangements toward obesity and the metabolic syndrome [present data and Ref. (21)]. Because obesity is a major risk factor for the development of the metabolic syndrome and type-2 diabetes (47-50), a food restriction regimen promoting weight loss should normalize the metabolic syndrome as well (51). Preventing hyperphagia using a pair-feeding protocol in subordinate mice completely abrogated body weight gain and visceral adiposity compared to subordinate mice that were fed ad libitum. This result has clear translational implications toward therapeutic interventions (52): offering the potential of treating obesity in a faster way (drugs are often effective after several weeks of treatment); treating obesity with non-pharmacological interventions effective for binge eating. Some of the involved peripheral mechanisms were here 
investigated, while the microstructural analysis of feeding could help pinpoint whether changes in meal parameter are due to altered negative feedback, which is mainly vagally mediated vs. altered palatability or motivation, which is mainly central nervous system in origin (53). Nevertheless, a lot remains to be established particularly at the central level. Previous studies [e.g., Ref. (13, $17,19,54-59)$ ] suggest that central peptidergic and monoaminergic pathways are likely candidates as the molecular substrate of the stress-associated BED-like syndrome. Food intake regulation indeed impinges on the integration of homeostatic and hedonic brain circuits, which mediate the drive for food intake depending on energy store levels and on rewarding properties of foods (60). Interestingly, hypothalamic levels of orexigenic peptides, such as NPY and AgRP, have indeed been found in the hypothalamus of hyperphagic subordinate mice (22). Despite progress have been made, future studies will need to be performed to identify the central pathways regulating subordination stress-induced BED-like syndrome.

In spite of the protective effects of preventing hyperphagia on obesity, pair feeding improved glucose tolerance but did not normalize fasting hyperglycemia (21). It is important to point out that the basal hyperglycemia of pair-fed subordinate mice was obtained in response to fasting and could indicate, in line with the results of the meal pattern analysis, more severe hunger-stress sensitivity, as highlighted by the parallel heightened corticosterone. Ghrelin is a hunger hormone previously associated with stress (22, 61-64) and decreased in the plasma of obese patients $(65,66)$. Fasting plasma ghrelin $(67,68)$ was decreased in subordinate ad libitum fed mice when compared to controls a finding in line with human studies, but it was normalized in subordinate pair fed mice. Conversely, other studies showed that the active form of ghrelin, i.e., acylghrelin, was increased in non-fasted subordinate mice in presence of increased $(22,69)$ or decreased $(70,71)$ weight gain. Although recent data suggest that also des-acyl-ghrelin might exert a biological activity, which appears to be independent from the GHSR-1a $(72,73)$, a limitation of the present study is that total and not acylghrelin was assessed. Accordingly, future studies are required to evaluate how CSS affects the active vs. inactive circulating level of this hormone if the levels are affected by fasting in similar models and subordinate mice also manifest a postprandial suppression of acyl-ghrelin levels as seen in patients.

In conclusion, we propose here a novel model of BED, which is characterized by spontaneous stress-associated binging episodes and is associated with the development of obesity and glucose intolerance. We also showed that preventing hyperphagia limits the development of diet-induced obesity. Our social subordination model convincingly provides a tool to access the mechanisms that amount to the regulation of eating behaviors both in health and pathological states, ultimately trying to deliver therapeutic solutions to human patients (74). A limitation of the CSS model is that it can only be applied to males. Indeed, laboratory bred female mice neither exhibit territorial aggression nor they manifest a robust social hierarchy (75). Nevertheless, models of BED have been validated and made available specifically in female mice (13). This creates the opportunity for an integrated comparative approach based on highly valid models for male and female mice and it holds the promise to highlight important aspects related to gender differences in BED observed in humans (76).

\section{ACKNOWLEDGMENTS}

This work was supported in part by NIH/NIA AG043972, UofMN Medical School and Minnesota Medical Foundation and to Alessandro Bartolomucci. Valentina Sanghez was supported by a graduate student fellowship of the University of Parma. Authors wish to thank Dr. Scott Crow for helpful discussion on bingeeating disorder, Dr. William Engeland for help with the corticosterone assay, and Dr. Paola Palanza and Dr. Stefano Parmigiani for support over the years; Ashish Jain, Jennifer Asturias, and Pietro Bonsanto for technical help. Role of funding source: the funding source had no role in the study design.

\section{REFERENCES}

1. Wilfley DE, Wilson GT, Agras WS. The clinical significance of binge eating disorder. Int J Eat Disord (2003) 34:S96-106. doi:10.1002/eat.10209

2. American Psychiatric Association. Diagnostic and Statistical Manual of Mental Disorders. (Vol. 5). Arlington, VA: American Psychiatric Publishing (2013).

3. National Task Force on the Prevention and Treatment of Obesity. Overweight, obesity, and health risk. Arch Int Med (2000) 160:898-904. doi:10.1001/archinte. 160.7.898

4. O’Connor DB, Jones F, Conner M, McMillan B, Ferguson E. Effects of daily hassles and eating style on eating behavior. Health Psychol (2008) 27(Suppl 1):S20-31. doi:10.1037/0278-6133.27.1.S20

5. Striegel-Moore RH, Dohm FA, Kraemer HC, Schreiber GB, Taylor CB, Daniels SR. Risk factors for binge-eating disorders: an exploratory study. Int J Eat Disord (2007) 40:481-7. doi:10.1002/eat.20400

6. Stein RI, Kenardy J, Wiseman CV, Dounchis JZ, Arnow BA, Wilfley DE. What's driving the binge in binge eating disorder? A prospective examination of precursors and consequences. Int J Eat Disord (2007) 40:195-203. doi:10.1002/eat.20352

7. Goldschmidt AB, Tanofsky-Kraff M, Goossens L, Eddy KT, Ringham R, Yanovski SZ, et al. Subtyping children and adolescents with loss of control eating by negative affect and dietary restraint. Behav Res Ther (2008) 46:777-87. doi:10.1016/j.brat.2008.03.004

8. Mathes WF, Brownley KA, Mo X, Bulik CL. The biology of binge eating. Appetite (2009) 52:545-53. doi:10.1016/j.appet.2009.03.005

9. Corwin RL, Buda-Levin A. Behavioral models of binge-type eating. Physiol Behav (2004) 82:123-30. doi:10.1016/j.physbeh.2004.04.036

10. Hagan MM, Chandler PC, Wauford PK, Rybak RJ, Oswald KD. The role of palatable food and hunger as trigger factors in an animal model of stress induced binge eating. Int J Eat Disord (2003) 34:183-97. doi:10.1002/eat.10168

11. Waters A, Hill A, Waller G. Internal and external antecedents of binge eating episodes in a group of women with bulimia nervosa. Int J Eat Disord (2001) 29:17-22. doi:10.1002/1098-108X(200101)29:1<17::AID-EAT3>3.3.CO;2-I

12. Mussell MP, Mitchell JE, Weller CL, Raymond NC, Crow SJ, Crosby RD. Onset of binge eating, dieting, obesity, and mood disorders among subjects seeking treatment for binge eating disorder. Int J Eat Disord (1995) 17:395-401. doi:10.1002/1098-108X(199505)17:4<395::AID-EAT2260170412>3.0.CO;2-I

13. Czyzyk TA, Sahr AE, Statnick MA. A model of binge-like eating behavior in mice that does not require food deprivation or stress. Obesity (2010) 18:1710-7. doi:10.1038/oby.2010.46

14. Cao X, Xu P, Oyola MG, Xia Y, Yan X, Saito K, et al. Estrogens stimulate serotonin neurons to inhibit binge-like eating in mice. J Clin Invest (2014) 124(10):4351-62. doi:10.1172/JCI74726

15. Bartolomucci A, Palanza P, Sacerdote P, Panerai AE, Sgoifo A, Dantzer R, et al. Social factors and individual vulnerability to chronic stress exposure. Neurosci Biobehav Rev (2005) 29:67-81. doi:10.1016/j.neubiorev.2004.06.009

16. Bartolomucci A. Social stress, immune functions and disease in rodents. Front Neuroendocrinol (2007) 28:28-49. doi:10.1016/j.yfrne.2007.02.001

17. Bartolomucci A, Pederzani T, Sacerdote P, Panerai AE, Parmigiani S, Palanza P. Behavioral and physiological characterization of male mice under chronic psychosocial stress. Psychoneuroendocrinology (2004) 29:899-910. doi:10.1016/ j.psyneuen.2003.08.003 
18. Bartolomucci A, Cabassi A, Govoni P, Ceresini G, Cero C, Berra D, et al. Metabolic consequences and vulnerability to diet-induced obesity in male mice under chronic social stress. PLoS One (2009) 4:e4331. doi:10.1371/journal.pone. 0004331

19. Bartolomucci A, Carola V, Pascucci T, Puglisi-Allegra S, Cabib S, Lesch KP, et al. Increased vulnerability to psychosocial stress in heterozygous serotonin transporter knockout mice. Dis Model Mech (2010) 3:459-70. doi:10.1242/dmm. 004614

20. Dadomo H, Sanghez V, Di Cristo L, Lori A, Ceresini G, Malinge I, et al. Vulnerability to chronic subordination stress-induced depression-like disorders in adult 129SvEv male mice. Prog Neuropsychopharmacol Biol Psychiatry (2011) 35(6):1461-71. doi:10.1016/j.pnpbp.2010.11.016

21. Sanghez V, De Santis V, Romano C, Franceschini P, Cero C, Dadomo H, et al. A mouse model of social-stress induced type 2 diabetes. Psychoneuroendocrinology (2013) 38(12):2933-42. doi:10.1016/j.psyneuen.2013.07.022

22. Patterson ZR, Khazall R, Mackay H, Anisman H, Abizaid A. Central ghrelin signaling mediates the metabolic response of $\mathrm{C} 57 \mathrm{BL} / 6$ male mice to chronic social defeat stress. Endocrinology (2013) 154(3):1080-91. doi:10.1210/en.20121834

23. Moles A, Bartolomucci A, Garbugino L, Conti R, Caprioli A, Coccurello R, et al. Psychosocial stress affects energy balance in mice: modulation by social status. Psychoneuroendocrinology (2006) 31:623-33. doi:10.1016/j.psyneuen.2006. 01.004

24. Bartolomucci A, Palanza P, Gaspani L, Limiroli E, Panerai AE, Ceresini G, et al. Social status in mice: behavioral, endocrine and immune changes are context dependent. Physiol Behav (2001) 73:401-10. doi:10.1016/S0031-9384(01) 00453-X

25. Bartolomucci A, Palanza P, Sacerdote P, Ceresini G, Chirieleison A, Panerai AE, et al. Individual housing induces altered immuno-endocrine responses to psychological stress in male mice. Psychoneuroendocrinology (2003) 28(4):540-58. doi:10.1016/S0306-4530(02)00039-2

26. Goebel M, Stengel A, Wang L, Taché Y. Central nesfatin-1 reduces the nocturnal food intake in mice by reducing meal size and increasing inter-meal intervals. Peptides (2011) 32(1):36-43. doi:10.1016/j.peptides.2010.09.027

27. Stengel A, Goebel M, Wang L, Rivier J, Kobelt P, Mönnikes H, et al. Activation of brain somatostatin 2 receptors stimulates feeding in mice: analysis of food intake microstructure. Physiol Behav (2010) 101(5):614-22. doi:10.1016/j. physbeh.2010.09.009

28. Wang L, Stengel A, Goebel M, Martinez V, Gourcerol G, Rivier J, et al. Peripheral activation of corticotropin-releasing factor receptor 2 inhibits food intake and alters meal structures in mice. Peptides (2011) 32(1):51-9. doi:10.1016/j. peptides.2010.10.017

29. Ellacott KL, Morton GJ, Woods SC, Tso P, Schwartz MW. Assessment of feeding behavior in laboratory mice. Cell Metab (2010) 12:10-7. doi:10.1016/j.cmet. 2010.06.001

30. Razzoli M, Karsten C, Yoder JM, Bartolomucci A, Engeland WC. Chronic subordination stress phase advances adrenal and anterior pituitary clock gene rhythms. Am J Physiol Regul Integr Comp Physiol (2014) 307(2):R198-205. doi:10.1152/ajpregu.00101.2014

31. Gluck ME. Stress response and binge eating disorder. Appetite (2006) 46(1):26-30. doi:10.1016/j.appet.2005.05.004

32. Finger BC, Dinan TG, Cryan JF. The temporal impact of chronic intermittent psychosocial stress on high-fat diet-induced alterations in body weight. Psychoneuroendocrinology (2011) 37(6):729-41. doi:10.1016/j.psyneuen.2011. 06.015

33. Solomon MB, Foster MT, Bartness TJ, Huhman KL. Social defeat and footshock increase body mass and adiposity in male Syrian hamsters. Am J Physiol Regul Integr Comp Physiol (2007) 292:R283-90. doi:10.1152/ajpregu.00330.2006

34. Hudson JI, Hiripi E, Pope HG Jr, Kessler RC. The prevalence and correlates of eating disorders in the national comorbidity survey replication. Biol Psychiatry (2007) 61:348-58. doi:10.1016/j.biopsych.2006.03.040

35. Wonderlich SA, Gordon KH, Mitchell JE, Crosby RD, Engel SG. The validity and clinical utility of binge eating disorder. Int J Eat Disord (2009) 42:687-705. doi:10.1002/eat.20719

36. Boggiano MM, Chandler PC. Binge eating in rats produced by combining dieting with stress. Curr Protoc Neurosci (2006) Chapter 9:Unit9.23A. doi:10.1002/0471142301.ns0923as36

37. Boggiano MM, Artiga AI, Pritchett CE, Chandler-Laney PC, Smith ML, Eldridge AJ. High intake of palatable food predicts binge-eating independent of susceptibility to obesity: an animal model of lean vs obese binge-eating and obesity with and without binge-eating. Int J Obes (Lond) (2007) 31:1357-67. doi:10.1038/sj.ijo.0803614

38. Strubbe JH, Woods SC. The timing of meals. Psychol Rev (2004) 111(1):128-41. doi:10.1037/0033-295X.111.1.128

39. Krebs H, Weyers P, Macht M, Weijers HG, Janke W. Scanning behavior of rats during eating under stressful noise. Physiol Behav (1997) 62(1):151-4. doi:10.1016/S0031-9384(97)00026-7

40. Harb MY, Reynolds VS, Campling RC. Eating behaviour, social dominance and voluntary intake of silage in group-fed milking cattle. Grass Forage Sci (1985) 40:113-8. doi:10.1111/j.1365-2494.1985.tb01727.x

41. Adami GF, Meneghelli A, Scopinaro N. Night eating and binge eating disorder in obese patients. Int J Eat Disord (1999) 25:335-8. doi:10.1002/(SICI)1098108X(199904) 25:3<335::AID-EAT12>3.0.CO;2-1

42. Adami GF, Campostano A, Marinari GM, Ravera G, Scopinaro N. Night eating in obesity: a descriptive study. Nutrition (2002) 8:587-9. doi:10.1016/S08999007(02)00761-X

43. Powers PS, Perez A, Boyd F, Rosemurgy A. Eating pathology before and after bariatric surgery: a prospective study. Int J Eat Disord (1999) 25:293-300. doi:10.1002/(SICI)1098-108X(199904)25:3<293::AID-EAT7>3.0.CO;2-G

44. Stunkard A, Berkowitz R, Wadden T, Tanrikut C, Reiss E, Young L. Binge eating disorder and the night-eating syndrome. Int J Obes Relat Metab Disord (1996) 20:1-6.

45. Greeno CG, Wing RR, Marcus MD. Nocturnal eating in binge eating disorder and matched-weight controls. Int J Eat Disord (1995) 18:343-9. doi:10.1002/ 1098-108X(199512)18:4<343::AID-EAT2260180407>3.0.CO;2-P

46. Grilo CM, Masheb RM. Night-time eating in men and women with binge eating disorder. Behav Res Ther (2004) 42:397-407. doi:10.1016/S0005-7967(03) 00148-7

47. Björntorp P. The origins and consequences of obesity. Diabetes. Ciba Found Symp (1996) 201:68-80.

48. Björntorp P, Rosmond R. The metabolic syndrome-a neuroendocrine disorder? Br J Nutr (2000) 83(Suppl 1):S49-57. doi:10.1017/S0007114500000957

49. Boden G. Obesity and diabetes mellitus - how are they linked? West Indian Med $J$ (2002) 51(Suppl 1):51-4.

50. Chan JM, Rimm EB, Colditz GA, Stampfer MJ, Willett WC. Obesity, fat distribution, and weight gain as risk factors for clinical diabetes in men. Diabetes Care (1994) 17:961-9. doi:10.2337/diacare.17.9.961

51. Aude YW, Mego P, Mehta JL. Metabolic syndrome: dietary interventions. Curr Opin Cardiol (2004) 19:473-9. doi:10.1097/01.hco.0000134610.68815.05

52. McElroy SL, Kotwal R, Malhotra S, Nelson EB, Keck PE, Nemeroff CB. Are mood disorders and obesity related? A review for the mental health professional. J Clin Psychiatry (2004) 65:634-51. doi:10.4088/JCP.v65n0507

53. Davis JD. A model for the control of ingestion - 20 years later. In: Morrison AR, Fluharty SJ, editors. Progress in Psychobiology and Physiological Psychology. (Vol. 17), San Diego, CA: Emerald Group Publishing Limited (1998). p. 127-73.

54. Dallman MF. Stress-induced obesity and the emotional nervous system. Trends Endocrinol Metab (2010) 21:159-65. doi:10.1016/j.tem.2009.10.004

55. Placidi RJ, Chandler PC, Oswald KD, Maldonado C, Wauford PK, Boggiano MM. Stress and hunger alter the anorectic efficacy of fluoxetine in binge-eating rats with a history of caloric restriction. Int J Eat Disord (2004) 36:328-41. doi:10.1002/eat.20044

56. Pankevich DE, Teegarden SL, Hedin AD, Jensen CL, Bale TL. Caloric restriction experience reprograms stress and orexigenic pathways and promotes binge eating. J Neurosci (2010) 30:16399-407. doi:10.1523/JNEUROSCI.1955-10.2010

57. Kishi T, Elmquist JK. Body weight is regulated by the brain: a link between feeding and emotion. Mol Psychiatry (2005) 10:132-46. doi:10.1038/sj.mp.4001638

58. Harris RB. Leptin - much more than a satiety signal. Annu Rev Nutr (2000) 20:45-75. doi:10.1146/annurev.nutr.20.1.45

59. Teske JA, Billington CJ, Kotz CM. Hypocretin/orexin and energy expenditure. Acta Physiol (Oxf) (2010) 198:303-12. doi:10.1111/j.1748-1716.2010.02075.x

60. Berthoud HR. The neurobiology of food intake in an obesogenic environment. Proc Nutr Soc (2012) 71:478-87. doi:10.1017/S0029665112000602

61. Asakawa A, Inui A, Kaga T, Yuzuriha H, Nagata T, Fujimiya M, et al. A role of ghrelin in neuroendocrine and behavioral responses to stress in mice. Neuroendocrinology (2001) 74:143-7. doi:10.1159/000054680

62. Kristenssson E, Sundqvist M, Astin M, Kjerling M, Mattsson H, Dornonville de la Cour C, et al. Acute psychological stress raises plasma ghrelin in the rat. Regul Pept (2006) 134:114-7. doi:10.1016/j.regpep.2006.02.003 
63. Ochi M, Tominaga K, Tanaka F, Tanigawa T, Shiba M, Watanabe T, et al. Effect of chronic stress on gastric emptying and plasma ghrelin levels in rats. Life Sci (2008) 82:862-8. doi:10.1016/j.lfs.2008.01.020

64. Zheng J, Dobner A, Babygirija R, Ludwig K, Takahashi T. Effects of repeated restraint stress on gastric motility in rats. Am J Physiol Regul Integr Comp Physiol (2009) 296:R1358-65. doi:10.1152/ajpregu.90928.2008

65. Tschöp M, Smiley DL, Heiman ML. Ghrelin induces adiposity in rodents. Nature (2000) 407:908-13. doi:10.1038/35038090

66. Shiiya T, Nakazato M, Mizuta M, Date Y, Mondal MS, Tanaka M, et al. Plasma ghrelin levels in lean and obese humans and the effect of glucose on ghrelin secretion. J Clin Endocrinol Metab (2002) 87(1):240-4. doi:10.1210/jcem.87.1.8129

67. Wren AM, Seal LJ, Cohen MA, Brynes AE, Frost GS, Murphy KG, et al. Ghrelin enhances appetite and increases food intake in humans. J Clin Endocrinol Metab (2001) 86:5992. doi:10.1210/jcem.86.12.8111

68. Wren AM, Small CJ, Abbott CR, Dhillo WS, Seal LJ, Cohen MA, et al. Ghrelin causes hyperphagia and obesity in rats. Diabetes (2001) 50:2540-7. doi: $10.2337 /$ diabetes.50.11.2540

69. Patterson ZR, Abizaid A. Stress induced obesity: lessons from rodent models of stress. Front Neurosci (2013) 7:130. doi:10.3389/fnins.2013.00130

70. Chuang JC, Cui H, Mason BL, Mahgoub M, Bookout AL, Yu HG, et al. Chronic social defeat stress disrupts regulation of lipid synthesis. J Lipid Res (2010) 51:1344-53. doi:10.1194/jlr.M002196

71. Chuang JC, Perello M, Sakata I, Osborne-Lawrence S, Savitt JM, Lutter M, et al. Ghrelin mediates stress-induced food-reward behavior in mice. J Clin Invest (2011) 121:2684-92. doi:10.1172/JCI57660

72. Toshinai K, Yamaguchi H, Sun YX, Smith RG, Yamanaka A, Sakurai T, et al. Des-acyl ghrelin induces food intake by a mechanism independent of the growth hormone secretagogue receptor. Endocrinology (2006) 147:2306-14. doi:10.1210/en.2005-1357

73. Gauna C, Delhanty PJ, van Aken MO, Janssen JA, Themmen AP, Hofland LJ, et al. Unacylated ghrelin is active on the INS-1E rat insulinoma cell line independently of the growth hormone secretagogue receptor type 1a and the corticotropin releasing factor 2 receptor. Mol Cell Endocrinol (2006) 251:103-11. doi:10.1016/j.mce.2006.03.040

74. Yanovski SZ, Sebring NG. Recorded food intake of obese women with binge eating disorder before and after weight loss. Int J Eat Disord (1994) 15(2): 135-50. doi:10.1002/1098-108X(199403)15:2<135::AID-EAT2260150205>3.0. $\mathrm{CO} ; 2-\mathrm{I}$

75. Palanza P. Animal models of anxiety and depression: how are females different? Neurosci Biobehav Rev (2001) 25(3):219-33. doi:10.1016/S0149-7634(01) 00010-0

76. Mitchison D, Mond J, Slewa-Younan S, Hay P. Sex differences in health-related quality of life impairment associated with eating disorder features: a general population study. Int J Eat Disord (2013) 46(4):375-80. doi:10.1002/eat.22097

Conflict of Interest Statement: The authors declare that the research was conducted in the absence of any commercial or financial relationships that could be construed as a potential conflict of interest.

Received: 16 September 2014; accepted: 17 December 2014; published online: 06 January 2015.

Citation: Razzoli M, Sanghez V and Bartolomucci A (2015) Chronic subordination stress induces hyperphagia and disrupts eating behavior in mice modeling binge-eating-like disorder. Front. Nutr. 1:30. doi: 10.3389/fnut.2014.00030

This article was submitted to Nutrition Methodology, a section of the journal Frontiers in Nutrition.

Copyright (c) 2015 Razzoli, Sanghez and Bartolomucci. This is an open-access article distributed under the terms of the Creative Commons Attribution License (CC BY). The use, distribution or reproduction in other forums is permitted, provided the original author(s) or licensor are credited and that the original publication in this journal is cited, in accordance with accepted academic practice. No use, distribution or reproduction is permitted which does not comply with these terms. 